\title{
Preparedness Perceptions of Environmental Health Graduates in Handling Emerging Public Health Concerns in Kenya
}

\author{
Jepngetich Hellen ${ }^{1, *}$, Nyamwange Caleb ${ }^{2}$, Baliddawa Joyce ${ }^{3}$, Karani Anna ${ }^{4}$ \\ ${ }^{1}$ Department of Environmental Health, School of Public Health, College of Health Sciences, Moi University, Eldoret, Kenya \\ ${ }^{2}$ Department of Biochemistry, School of Medicine, College of Health Sciences, Moi University, Eldoret, Kenya \\ ${ }^{3}$ Department of Behavioural Sciences and Ethics, School of Medicine, College of Health Sciences, Moi University, Eldoret, Kenya \\ ${ }^{4}$ Department of Nursing, College of Health Sciences, University of Nairobi, Nairobi, Kenya
}

Email address:

jepngetichkeny@gmail.com (J. Hellen)

${ }^{*}$ Corresponding author

\section{To cite this article:}

Jepngetich Hellen, Nyamwange Caleb, Baliddawa Joyce, Karani Anna. Preparedness Perceptions of Environmental Health Graduates in Handling Emerging Public Health Concerns in Kenya. American Journal of Health Research. Vol. 6, No. 3, 2018, pp. 74-78.

doi: 10.11648/j.ajhr.20180603.12

Received: June 13, 2018; Accepted: July 9, 2018; Published: August 15, 2018

\begin{abstract}
Background: Public Health workforce faces varied challenges ranging from workforce shortages to debates on relevance and the adequacy of their training. This is particularly true to graduates undertaking Bachelor of Science degree in Environmental Health (BSc EVH) because of the wide areas in the job market that they can be absorbed into. Consequently there are concerns of mismatch between the academic training and their job market demands and expectation which hinge on the preparedness of these graduates to handle public health activities and obligations. Aim: The purpose of this study was to assess the graduates' preparedness to handle emerging public health concerns. Methods: A cross-sectional descriptive study design employing both quantitative and qualitative methods was done from September 2016 to April 2017. The graduates were stratified by year of graduation and a total of 229 were randomly recruited into the study. The participants were interviewed using a pretested semi-structured questionnaire. An interviewer guide was also used to further interrogate graduates. Data was analyzed for proportions and associations using statistical package for social sciences (SPSS) version 20. Results: Among 188 graduates that completed the questionnaires, $79(42 \%)$ were aged 25-34 years, 71(37.8\%) aged 35-44 years, 29(15.4\%) aged 45 -54 and $9(4.8 \%)$ were $\leq 25$ years. More than half $(111(59 \%)$ of the graduates were males. All graduates were distributed over more than 12 public health career areas. On preparedness, $123(65.4 \%)$ perceived to be prepared to handle emerging public health challenges whereas $65(34.6 \%)$ said that they were unprepared. Among those who reported that they were prepared, there was a higher median competence score compared to those who opined that they were not prepared ( $2.93 \mathrm{vs} 2.79, \mathrm{Z}=2.472$ and $\mathrm{p}=0.013$ ). A unit increase in the competence score indicates increased chance of being prepared by $10.6 \%$ (OR; 1.106 ; $95 \%$ CI: $1.042-1.174, p=0.001$ ). Conclusion: Our findings indicate that majority of the graduates perceived to be prepared to handle emerging public health concerns though a significant $34.6 \%$ felt that they were inadequately prepared. Therefore the depth of specific course content and implementation is still an area of concern to graduates. Recommendation: Forge and strengthen collaborations between the training institutions and the practitioner organizations to tailor graduate training to industry requirements.
\end{abstract}

Keywords: Preparedness, Perceptions, Emerging Public Health Concerns, Environmental Health Graduate

\section{Introduction}

Environmental health is a rapidly evolving field of study and practice and professionals working in this field have to deal with increasingly complex situations in their work stations. They face a range of challenges ranging from demographic transition, natural disasters, epidemics to ill 
health that is worsened by poverty particularly those living in resource constrained countries [1] and global threats such as terrorism activities.[2] All these critical situations of public health need specialized knowledge and effectiveness among public health professionals. However, published reports indicate that there are professionals who may lack the requisite skills despite being fully trained [3]. This lack of congruence between what is taught and what is required at the work place could result in lack of confidence on public health practitioners by the prospective employers [4].

Since the $20^{\text {th }}$ century, there has been integration of modern science content into the public health curricula at the universities and other institutions of higher learning but despite this, fresh health challenges that threaten the health of the public still loom [5]. Public Health occurrences such as disasters and disease outbreaks coupled with political changes clearly indicate that the challenges faced are not static, but can change considerably in a short time. This therefore calls for adequate training in competencies required for Environmental health practitioners to handle all possible scenarios in public health and research. Despite this, competency training framework has not been adequately developed to fit the African settings [6]. Comparatively, the more developed countries have organizations regulating competencies for example the Pan American Association of Public Health (PAHO) [7]. Additionally, Whittaker et al (2010) has reported that the association of schools of public health in the European regions (ASPHER) is in the process of initiating a public health competency framework by organizing brainstorming workshops on professional public health competencies [8]. Curriculum development in Environmental Health education and training ought to form part of the public health competency framework that can be used to identify needs for EVH capacity building worldwide as new priorities and challenges arise $[9,10,11]$. It is true that countries worldwide ranging from United States, United Kingdom, and Nigeria experience public health incidents that change considerably in a short time thus indicating that public health practitioners' ought to be ready and equipped to change so as to meet the demands and challenges. This notwithstanding, public health workforce research has focused more on categorical issues rather crosscutting issues yet what is evident is the need for competent work force infrastructure to compliment other public health structures for a better focus on public health challenges $[12,13]$

Indeed public health has evolved over decades and workforce development has been evolving too. Criticism on workforce training has been strong as evidenced by a report in 1988 by institute of medicine on the future of public health in general which states that building stronger public health workforce competency for the future is lacking and is impacting negatively on the health of populations [14]. Consequent to this report, schools of public health, professional bodies, federal agencies, and employers were called to remedy the situation.[15] The Institute of Medicine report of 2000 records some success to this effect, but a lot of work remains [16]. Evidently, workforce development has been a much needed discourse and indeed great changes have been reported though with greater emphasis has been on strengthening health systems [5]. Even with this, there are frequent occurrences of health insecurities and concerns which have been recurrent despite health professional being continually being trained and released to the labour market. This raises the question on the adequacy and preparedness of the public health professionals churned out of training institutions. Further, the workforce faces a crisis in the face of changing training demands evidenced by gaps in the existing training programs. There is therefore need to identify these training needs for public health professionals which will then ploughed back into the curriculum to equip future graduates for better outcomes $[17,18]$

\section{Objective}

The objective of the study was to explore the graduates' perceptions on their preparedness to handle emerging public health challenges.

\section{Methodology}

A cross sectional study that involved both qualitative and quantitative methods were used in the study. The quantitative aspect involved the use of pretested semi structured questionnaires for the graduates. Further in-depth interviews were also done at a later time with the graduates for more insights on issues that sprung up from the responses in the structured questionnaire.

The study targeted a sample of 229 graduates using existing records at the School of Public Health. The graduates were stratified by year of graduation then proportionately recruited into the study. Contacts of mobile telephone numbers and email addresses of the sampled were retrieved for purposes of communication. The data was then collected through an online survey. In this regard, an introductory letter was send through their email addresses as well as through their mobile phones in form of a text message. An informed consent was then sent together with a link containing the survey questions. Only those who consented to participate in the study were directed to the link of survey questions while those declining were thanked and wished a good day.

In addition, in-depth interviews were used to collect additional information to triangulate the responses from the questionnaires. A total of 22 graduates working in various organization were interviewed. The interviewer subjected every graduate to the same format of similar questions. An audio recorder was used during the interviews which were later transcribed

Descriptive data was summarized and analyzed using frequencies, modes, means and standard deviation. The findings from the in depth interviews were transcribed into written words and used for narrations.

Ethical approval was obtained from Institutional Research and Ethics Committee (IREC), a College of Health Sciences, 
Moi University and the Moi Teaching and Referral Hospital committee. Informed consent was sought from all the participants. Participation was voluntary and the information provided was treated with confidentiality and anonymity.

\section{Results}

\subsection{Graduate Demographic Characteristics}

Among 188 graduates that completed the questionnaires, $79(42 \%)$ were aged $25-34$ years, $71(37.8 \%)$ aged $35-$ 44years, $29(15.4 \%)$ aged $45-54$ and $9(4.8 \%)$ were $\leq 25$ years. More than half (111(59\%) were males while 28(36.4\%) were females. Further analysis revealed no relationship between graduate demographic characteristics and preparedness (Age group chi $=0.940 \mathrm{P}$ value $=0.816$, Gender $\mathrm{z}=1.662 \mathrm{P}$ value $=0.096)$.

\subsection{Graduates Experience with Current Employer and Preparedness}

The Kruskal wallis test revealed a chi value of 7.872 and $p$ value of 0.049 between the graduates who were prepared and those not prepared in the varying categories of work experience with current employer. These findings revealed a significant relationship between experience (years worked with current employer) and preparedness to handle emerging public health challenges chi $=7.872, \mathrm{p}=0.049$ ). Higher proportion of those who had worked for more than 5 years were more prepared compared to those who had worked for less than 1 and 3 years $(81 \%$ and $71 \%)$ respectively.

\subsection{Graduates Perception on Their Preparedness to Handle Emerging Public Health Challenges}

More than half of the graduates $123(65.4 \%)$ perceived to be prepared to handle emerging public health challenges while $65(34.6 \%)$ perceived to be unprepared. These who perceived not to be prepared cited challenges such as problems in translating theory to practice, inexperience, of lack of field exposure, soft skills and poor confidence in public forum activities as exemplified by the narrations below;

........ I possess the skills, but in theory. Being in the field was a huge frustration......at some point I was told to that I needed to "grow wings.........

38 year old IDI

Even though more than half perceived to be prepared, they reported discontentedness on the content and depth of their training as reported by one of the respondent who said;

“........Very little was taught on disaster preparedness, yet when out here I need to know a lot on it like regulations and litigations which were never mentioned during my training......"

Other graduates were particularly concerned on the scope of the training done with most of them indicating that the training was not tailored to local situations. This lead to missed opportunities to identify local and regional public health disasters that needed appropriate and sustainable mitigation strategies.

".......the scope on disaster management was misleading....during my time, I only heard a little on international disasters used as examples as if there were none within our own setup. It hurts having such a nice course with major units with students gaining very little.....no wonder few graduates' engage in this field.........

The graduates who perceived not to be adequately prepared gave various reasons for the inadequacies. These included inadequate practical sessions, lack of hands on training, missing aspect on monitoring and evaluation as well as lack of field exposure to real life experiences as exemplified by the narration below.

"....the training was purely theoretical..... I would love if the department could establish laboratories for conducting water and safety quality....."

\subsection{Association Between Competence and Preparedness to Handle Emerging Public Health Challenges}

On testing the association between competence and preparedness to handle emerging public health challenges, there was a significant difference in the median score between graduates who were prepared to handle emerging public health challenges and those who were not. Those prepared had a higher median competence score compared to those not prepared (2.93 vs $2.79, \mathrm{Z}=2.472$ and $\mathrm{p}=0.013$ ) respectively. Similarly, Simple binary logistic regression indicated that a unit increase in the competence score increased the chances of being prepared by $10.6 \%$ (OR; 95\%CI: $1.106 ; 1.042-1.174, \mathrm{p}=0.001$ )

\section{Discussion}

Findings from the study indicate that more than half of the graduates $123(65.4 \%)$ perceived to be prepared to handle emerging public health challenges while 65(34.6\%) perceived that they were unprepared. These results are consistent with the findings of a study done by Hsu and team in Texas, United States of America on public health preparedness of health providers where out of the $73.2 \%$ healthcare workers trained in emergency response, only $45.8 \%$ were prepared to respond to public health emergencies [19]. Nevertheless, the proportion of the graduates who perceived unprepared after all the years of training is a major concern. This is contrary to the fact that employers want better prepared graduates and students are asking to be trained to be employable too.[20] However, these findings are not different from the findings of Markenson et al (2005) where they found out that despite extensive training in public health emergencies, the practitioners still felt unprepared for emergencies [2] This study findings are further supported by Subbarao et al (2008) who in their study based on educational framework alludes that preparedness is a process and competencies must be reviewed over time [21]. Therefore continuing professional development of environmental health practitioners is necessary for them to be 
on the forefront in disease prevention and surveillance. In fact strengthening the capacity of these professionals goes a long way in meeting the World Health Organization's goal of preparedness and an aspect of strengthening institutional and human resource management [22, 23] These findings therefore constitutes an important aspect and an opportunity for the employers particularly at the national and county government to use these graduates for preparedness planning.

Findings from in-depth interviews revealed issues of training related to the curriculum content and scope. The training content seemed to be below the job demands and that the content was inadequate hence graduates believed that they were not sufficiently prepared to handle emerging public health challenges [24-26] The in depth interviews indicated that majority of the healthcare workers portrayed willingness to participate in public health emergencies, therefore called for adequate and proper training. The results on these studies and the current study underscore the importance of developing tailored educational approaches to address the needs of graduates so as to meet market demands.

Regarding graduates years worked and preparedness, the findings revealed a relationship between the number of years worked and preparedness to handle public Health challenges (chi $=7.872, \mathrm{p}=0.049$ ). This could probably be due to the on job training as well as the graduates' field experiences. This study findings concurs with a descriptive study on nurses perception to respond to major disasters which observed that those with prior experience were confident in handling disasters [23] These findings further concurs with Gebbie's et al (2002) which found that no two emergencies or disasters were alike, but in each situation, competencies for effective response were the same and depended on the healthcare workers experience [27].

This study findings further revealed that a unit increase in the competency score increases the graduates chances of being prepared by $10.6 \%$ (OR; 95\%CI: 1.106; 1.042-1.174, $\mathrm{p}=0.001)$. This agrees with Hoges et al (2005) who avers that there is need to focus and direct attention to the competency boosting of health care workers for better healthcare outcomes [28] Additionally this study findings is consistent to the findings of a research done on emergency preparedness competencies of public health inspectors in China by Ning Ning et al (2014) on emergency preparedness competencies of public health inspectors which found significant differences among inspectors competency domains as per adjusted odds regression levels [29].

\section{Conclusion}

From the findings and the discussions, it can be deduced that graduates perceived themselves to be prepared to handle emerging public health challenges though a significant $34.6 \%$ felt they were not well prepared. Competency scores influenced the graduates' preparedness and that graduates' experience in the field and the length of working years improved their work competencies. There are training concerns on content and scope of specific course units' in relation to job demands.

\section{Recommendations}

The study recommends collaboration between the higher education management and practitioner organization to relook into the curriculum content and tailor to meet educational approaches. This will enhance competency scores that will have ripple effects on the graduates' preparedness.

\section{Acknowledgements}

The research was supported by the Consortium for Advanced Research Training in Africa (CARTA). CARTA is jointly led by the Africa Population and Research Centre (APHRC) and the University of Witwatersrand. CARTA is jointly led by the African Population and Health Research Center and the University of the Witwatersrand and funded by the Carnegie Corporation of New York (Grant No--B 8606. R02), Sida (Grant No:54100029), the DELTAS Africa Initiative (Grant No: 107768/Z/15/Z). The DELTAS Africa Initiative is an independent funding scheme of the African Academy of Sciences (AAS)'s Alliance for Accelerating Excellence in Science in Africa (AESA) and supported by the New Partnership for Africa's Development Planning and Coordinating Agency (NEPAD Agency) with funding from the Wellcome Trust (UK) and the UK government, " The statements made and views expressed are solely the responsibility of the authors.

\section{References}

[1] Grimm, B. L., et al., Assessing the Education and Training Needs of Nebraska's Public Health Workforce. Front Public Health, 2015. 3: p. 161.

[2] Markenson, D., C. DiMaggio, and I. Redlener, Preparing health professions students for terrorism, disaster, and public health emergencies: core competencies. Academic Medicine, 2005. 80(6): p. 517-526.

[3] Walsh, L., et al., Core competencies for disaster medicine and public health. Disaster medicine and public health preparedness, 2012. 6(01): p. 44-52.

[4] Abbas, S. M., A. Lee, and H. Mubashir, Competencies required from public health professionals by health based organisations and the role of academia. J Pak Med Assoc, 2014. 64(1): p. 57-63.

[5] Frenk, J., et al., Health professionals for a new century: transforming education to strengthen health systems in an interdependent world. The lancet, 2010. 376(9756): p. 1923-1958.

[6] Parker, B. and S. Walters, Competency based training and national qualifications frameworks: Insights from South Africa. Asia Pacific Education Review, 2008. 9(1): p. 70-79.

[7] Britten, N., et al., Using core competencies to build an evaluative framework: outcome assessment of the University of Guelph Master of Public Health program. BMC Med Educ, 2014. 14: p. 158.[ 
[8] Whittaker, P. J., et al., Do academic competencies relate to 'real life' public health practice? A report from two exploratory workshops. Eur J Public Health, 2010. 20(1): p. 8-9.

[9] Czabanowska, K., et al., Do we develop public health leaders? association between public health competencies and emotional intelligence: a cross-sectional study. BMC Med Educ, 2014. 14: p. 83 .

[10] Bell, J., et al., Developing a new public health cadre to meet the demands of midwifery care in Malawi. Perspect Public Health, 2014. 134(5): p. 248-9.

[11] Fineberg, H. V., et al., Changing public health training needs: professional education and the paradigm of public health. Annual Review of Public Health, 1994. 15(1): p. 237-257.

[12] Australia, S., Australian workforce futures: A national workforce development strategy. 2010: Skills Australia.

[13] Giloth, R. P., Learning from the field: Economic growth and workforce development in the 1990s. Economic Development Quarterly, 2000. 14(4): p. 340-359.

[14] Walker Jr, B., The future of public health: the Institute of Medicine's 1988 report. Journal of public health policy, 1989. 10(1): p. 19-31.

[15] Chassin, M. R. and R. W. Galvin, The urgent need to improve health care quality: Institute of Medicine National Roundtable on Health Care Quality. Jama, 1998. 280(11): p. 1000-1005.

[16] McDonald, C. J., M. Weiner, and S. L. Hui, Deaths due to medical errors are exaggerated in Institute of Medicine report. Jama, 2000. 284(1): p. 93-95.

[17] Jacobs, J. and K. J. Dougherty, The uncertain future of the community college workforce development mission. New Directions for Community Colleges, 2006. 2006(136): p. 53-62.

[18] Union, A. Strategy to revitalize technical and vocational education and training (TVET) in Africa. in Meeting of the Bureau of the Conference of Ministers of Education of the African Union (COMEDAF II+). 2007.

[19] Hsu, C. E., et al., Public health preparedness of health providers: meeting the needs of diverse, rural communities. Journal of the National Medical Association, 2006. 98(11): p. 1784 .
[20] Docherty, D., Universities must produce graduates who are ready for any workplace. The Guardian, 2014.

[21] Subbarao, I., et al., A consensus-based educational framework and competency set for the discipline of disaster medicine and public health preparedness. Disaster medicine and public health preparedness, 2008. 2(01): p. 57-68.

[22] Organization, W. H., Essential public health functions: a threecountry study in the Western Pacific Region. 2003: Manila: WHO Regional Office for the Western Pacific.

[23] Baack, S. and D. Alfred, Nurses' preparedness and perceived competence in managing disasters. Journal of Nursing Scholarship, 2013. 45(3): p. 281-287.

[24] Slepski, L. A., Emergency preparedness and professional competency among health care providers during hurricanes Katrina and Rita: pilot study results. Disaster management \& response, 2007. 5(4): p. 99-110.

[25] Alexander, G. C. and M. K. Wynia, Ready and willing? Physicians' sense of preparedness for bioterrorism. Health Affairs, 2003. 22(5): p. 189-197.

[26] Keim, M. E., Building human resilience: the role of public health preparedness and response as an adaptation to climate change. American journal of preventive medicine, 2008. 35(5): p. 508-516.

[27] Gebbie, K. and J. Merrill, Public health worker competencies for emergency response. Journal of Public Health Management and Practice, 2002. 8(3): p. 73-81.

[28] Hoge, M. A., J. Tondora, and A. F. Marrelli, The fundamentals of workforce competency: Implications for behavioral health. Administration and Policy in Mental Health and Mental Health Services Research, 2005. 32(5-6): p. 509-531.

[29] Ning, N., et al., Factors affecting emergency preparedness competency of public health inspectors: a cross-sectional study in northeastern China. BMJ open, 2014. 4(1): p. e003832. 